\title{
Prevalence of Sjögren's syndrome associated with rheumatoid arthritis in the USA: an observational study from the Corrona registry
}

\author{
Leslie R. Harrold ${ }^{1,2}$ (D) Ying Shan $^{1} \cdot$ Sabrina Rebello ${ }^{1}$ (i) $\cdot$ Neil Kramer $^{3} \cdot$ Sean E. Connolly ${ }^{4}$ Evo Alemao ${ }^{4}$. \\ Sheila Kelly ${ }^{4} \cdot$ Joel M. Kremer ${ }^{5} \cdot$ Elliot D. Rosenstein $^{3}$ (I)
}

Received: 31 January 2020 /Revised: 31 January 2020 / Accepted: 17 February 2020 / Published online: 4 March 2020

(C) The Author(s) 2020

\begin{abstract}
The objectives of this analysis were to assess the prevalence of Sjögren's syndrome (SS) associated with rheumatoid arthritis (RA) and to compare baseline characteristics of patients with RA with and without SS. Adult patients with RA from a large observational US registry (Corrona RA), with $\geq 1$ visit for assessment of SS status between 22 April 2010 and 28 February 2018 , were considered. Patients with RA with versus without SS were compared. SS status was determined from a yes/no variable and reported at enrollment into the Corrona RA registry and follow-up visits. Outcomes were unadjusted prevalence of SS in patients with RA, prevalence of SS by RA disease duration, and baseline characteristics in patients with RA by SS status. Of 24,528 eligible patients, 7870 (32.1\%) had a diagnosis of RA and SS. The unadjusted overall rate for SS prevalence in patients with RA was 0.30 (95\% confidence interval $0.29,0.31)$. SS prevalence increased with increasing RA duration. Patients with RA with versus without SS were more likely to be older, female, and seropositive; had a longer RA duration; higher disease activity; and a higher incidence of comorbidities (hypertension, cardiovascular disease, malignancies, and serious infections), erosive disease, and subcutaneous nodules at index date. Patients with RA and SS had a higher disease burden than those with RA only. The prevalence of SS increased as duration of RA increased. RA with SS was associated with seropositivity, more severe RA, extraarticular manifestations, and comorbidities.

\section{Key Points}

- The overall prevalence of SS among patients with RA was $30 \%$.

- The prevalence of SS increased with increasing RA disease duration.

- Identifying specific clinical characteristics of patients with RA with SS, such as a greater incidence of extra-articular manifestations and comorbidities, may help clinicians to better characterize this patient population.
\end{abstract}

Keywords Observational study $\cdot$ Prevalence $\cdot$ Rheumatoid arthritis $\cdot$ Sjögren's syndrome

Leslie R. Harrold

lharrold@corrona.org

1 Corrona, LLC, 1440 Main Street, Suite 310, Waltham, MA 02451, USA

2 University of Massachusetts Medical School, Worcester, MA, USA

3 Institute for Rheumatic \& Autoimmune Diseases, Overlook Medical Center, Summit, NJ, USA

4 Bristol-Myers Squibb, Princeton, NJ, USA

5 Albany Medical College and the Center for Rheumatology, Albany, NY, USA

\section{Introduction}

Sjögren's syndrome (SS) is a systemic autoimmune disease with a wide variety of presentations which can be characterized as either glandular (e.g., dry eyes and/or mouth) or extraglandular (e.g., musculoskeletal, cutaneous, neurologic, pulmonary, or renal) manifestations $[1,2]$. SS frequently occurs with another autoimmune disease such as rheumatoid arthritis (RA) [2, 3]; however, the prevalence and characterization of SS associated with RA are poorly understood [2, 4-6]. SS is commonly classified as "primary" or "secondary," depending on whether or not a coexisting autoimmune condition is present. Recent publications, however, favor more descriptive terms, such as "SS alone" or "SS associated with systemic or organ-specific autoimmune diseases." This trend 
has been developed to more accurately describe secondary SS in terms of which autoimmune disease is associated with SS and because the autoimmune conditions are coexisting rather than one being secondary to another [3].

A meta-analysis of 18 studies investigating SS associated with RA found a global prevalence of $19.5 \%$ [7]. Prevalence data for SS associated with RA in the USA are limited; one registry reported a rate of $10.3 \%$ [8]. Rate estimates from several European studies range from 7 to $31 \%$ [9-11]. The presence of SS adds to the RA disease burden, negatively impacts patients' daily lives, and is associated with increased comorbidities, pain, fatigue, and joint damage, and a higher mortality rate $[8,12,13]$.

SS may be a marker of more aggressive joint disease in patients with RA [8]; thus, identifying specific characteristics for patients with RA with SS may help clinicians to better characterize this population. The aims of this analysis were to assess the prevalence of SS associated with RA and to compare baseline characteristics of patients with RA with and without SS in the USA.

\section{Materials and methods}

\section{Data source}

The Corrona RA registry is an independent, prospective, national, observational cohort. Patients are recruited from 182 private and academic practice sites across 42 US states, with 781 participating rheumatologists. As of June 2019, the Corrona RA registry included information on 52,757 patients. Data on 397,236 patient visits and approximately 188,161 patient-years of follow-up time have been collected, with a mean (standard deviation [SD]) patient follow-up of 4.5 (3.8; median, 3.3) years.

\section{Study population}

Patients aged $\geq 18$ years with rheumatologist-diagnosed RA enrolled in the Corrona RA registry between 22 April 2010 and 28 February 2018 were included. SS status was determined from a yes/no variable based on physician diagnosis, reported into the Corrona RA registry at enrollment/followups. For SS patients, the index date was defined as the date the provider first reported SS status as yes, and for patients without SS, it was the date on which the provider first reported SS status as no. Patients were included if they had $\geq 1$ visit assessing the SS status (yes/no) and $\geq 12$ months of followup after the index date to allow time for SS diagnosis. Patients with missing SS information were excluded. The presence of SS was determined by the clinical signs and symptoms of dry eyes, and/or dry mouth, unrelated to medications. Physician forms included a yes/no question regarding secondary SS status. Baseline was defined as the index visit in which a patient first reported a diagnosis of SS and RA or RA alone.

\section{Study outcomes}

The primary outcome was the unadjusted prevalence of physician-reported SS associated with RA. Secondary outcomes included unadjusted prevalence of SS by RA disease duration and assessment of patients' baseline characteristics by SS status.

\section{Statistical analysis}

Unadjusted prevalence rate for SS associated with RA was calculated, using the proportion exact confidence intervals by Stata Software (version 15.1), excluding patients without 12-month follow-up after first SS report. For both prevalence of SS associated with RA and SS by RA disease duration, the 95\% confidence intervals (CI) for the proportion of patients with SS alone and SS associated with RA were calculated based on a normal distribution. Baseline characteristics were summarized using descriptive statistics; frequency and percentage were calculated for categorical variables and means (SD) were calculated for continuous variables. Health status was measured by the five domains of the EuroQoL 5dimension questionnaire: mobility, self-care, usual activities, pain/discomfort, and anxiety/depression [14]. All analyses were performed using Stata Release 15 (StataCorp LLC, College Station, TX, USA).

\section{Results}

\section{Patient disposition}

Data were available for 35,156 patients with RA who had a known SS status, of whom 24,528 patients had at least 12 months of follow-up (Fig. 1). Approximately one-third of patients had RA with SS $(n=7870 ; 32.1 \%)$.

\section{Prevalence of SS in patients with RA}

The unadjusted rate (excluding patients with $<12$ months of follow-up) for the prevalence of SS in patients with RA was $30.0 \%$ (95\% CI $29.4 \%, 30.6 \%$ ). The unadjusted SS rate increased with RA disease duration from $14.4 \%$ in patients with disease duration of 0 to 1 years to $38.8 \%$ in patients with disease duration of $>10$ years (Fig. 2).

\section{Clinical characteristics}

Compared with patients with RA only, patients with RA with SS were more likely to be female, older and have longer RA 
Fig. 1 Patient disposition. Asterisk indicates yes/no to having SS. Dagger mark indicates after the first capture of SS data in patients with a diagnosis of no SS. $\mathrm{RA}=$ rheumatoid arthritis; $\mathrm{SS}=$ Sjögren's syndrome

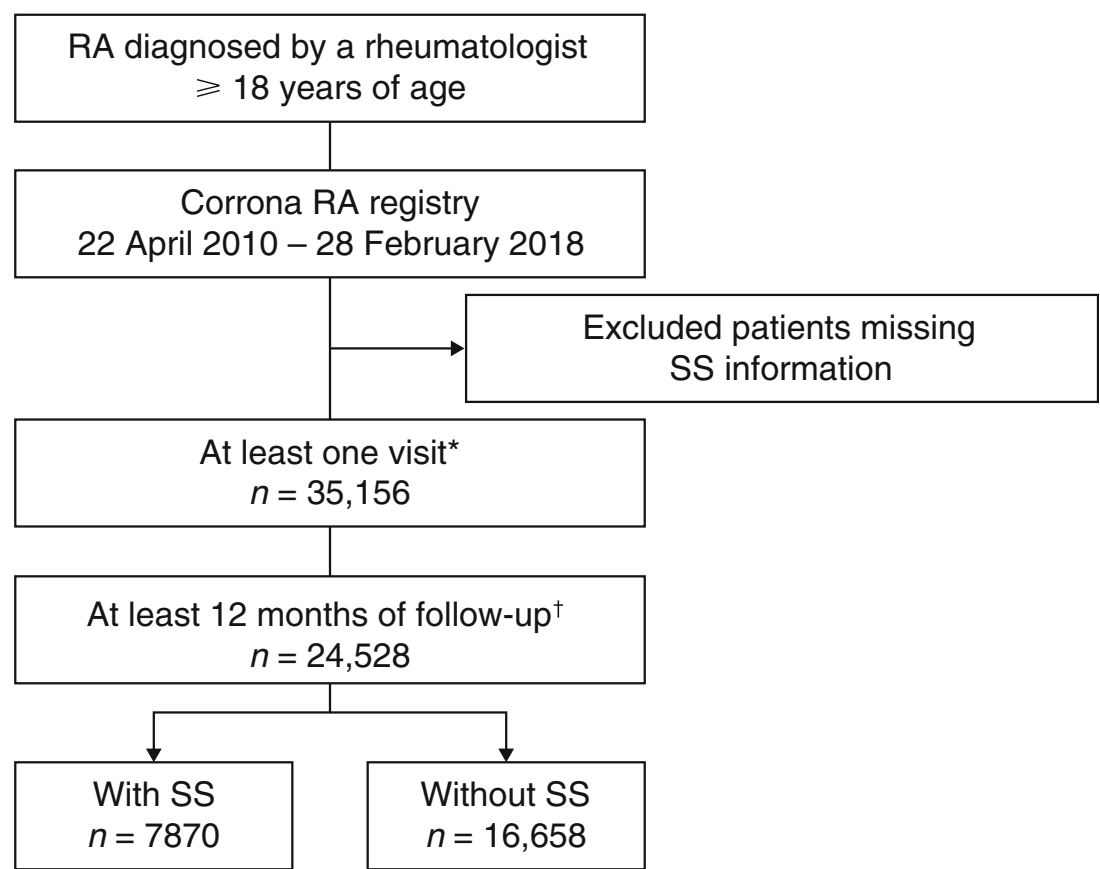

disease duration (Table 1). There were fewer patients with RA with SS in full-time employment and more disabled or retired patients compared with patients with RA only. Patients with RA with SS had more baseline comorbidities (hypertension, cardiovascular disease, and malignancies), erosive disease, and subcutaneous nodules than patients with RA only. Patients with RA with SS experienced twice the incidence of serious infections requiring hospitalization or intravenous treatment than patients with RA only. Patients with RA with SS, versus RA only, were more likely to be seropositive (anticyclic citrullinated peptide-positive, rheumatoid factor-positive, and double-positive) and have a higher mean clinical disease activity index score (Table 1). Patients with RA with SS were more likely to be taking abatacept or other non-tumor necrosis factor inhibitor biologic/targeted synthetic (ts) disease-modifying antirheumatic drugs (DMARDs) than patients with RA only. Additionally, they were more likely to have previously used $>1$ conventional synthetic DMARD and biologic/tsDMARD (Table 1). Compared with patients with RA only, patients with RA with SS were more likely to have experienced morning stiffness and have higher mean modified health assessment questionnaire [15], patient pain, and Patient Global Assessment scores. Patients with RA with SS were more likely to report difficulties with walking, self-care, usual

Fig. 2 Unadjusted prevalence of SS in patients with RA by duration of disease. Asterisk indicates patients included in analysis $=7077$. $\mathrm{RA}=$ rheumatoid arthritis; $\mathrm{SS}=$ Sjögren's syndrome

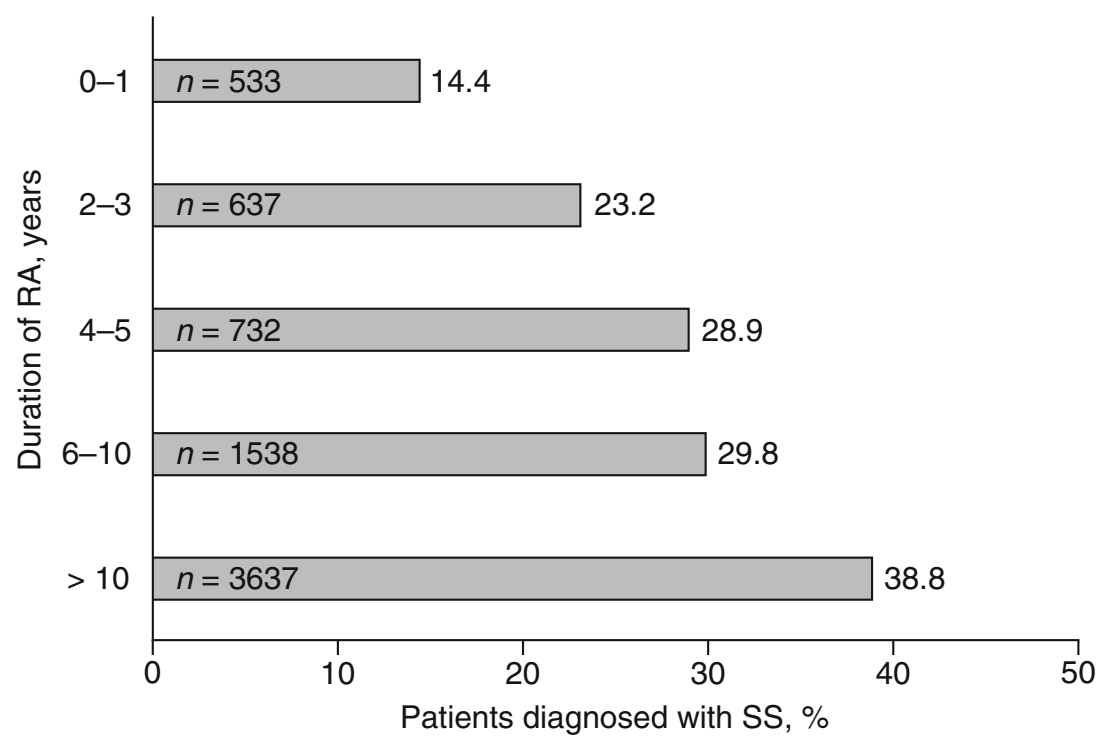


Table 1 Patient demographic and clinical characteristics at index date

\begin{tabular}{|c|c|c|}
\hline & $\begin{array}{l}\text { Patients with RA } \\
\text { with SS } \\
(n=7870)\end{array}$ & $\begin{array}{l}\text { Patients with RA } \\
\text { only } \\
(n=16,658)\end{array}$ \\
\hline Age, years, mean (SD) & $62.5(11.9)$ & $59.2(13.1)$ \\
\hline Sex, female & $6617(84.4)$ & $12,229(73.8)$ \\
\hline $\begin{array}{l}\text { Duration of RA, years, mean } \\
\text { (SD) }\end{array}$ & $13.6(11.0)$ & $9.5(9.2)$ \\
\hline Work status & $n=7692$ & $n=16,373$ \\
\hline Full-time & $2142(27.8)$ & $6530(39.9)$ \\
\hline Part-time & $607(7.9)$ & $1389(8.5)$ \\
\hline Disabled & $1237(16.1)$ & $1716(10.5)$ \\
\hline Retired & $2986(38.8)$ & 5169 (31.6) \\
\hline Other & $720(9.4)$ & $1569(9.6)$ \\
\hline \multicolumn{3}{|l|}{ Comorbidities } \\
\hline Hypertension & $2909(37.0)$ & $5214(31.3)$ \\
\hline CV disease* & $1219(15.5)$ & $1710(10.3)$ \\
\hline Malignancy $^{\dagger}$ & $1223(15.5)$ & $1821(10.9)$ \\
\hline Serious infections & $795(10.1)$ & $845(5.1)$ \\
\hline Diabetes & $775(9.8)$ & $1416(8.5)$ \\
\hline Asthma & $403(5.1)$ & $590(3.5)$ \\
\hline COPD & $270(3.4)$ & $355(2.1)$ \\
\hline ILD/pulmonary fibrosis & $81(1.0)$ & $81(0.5)$ \\
\hline Anti-CCP-positive, n/m (\%) & $1999 / 3420(58.5)$ & $4076 / 7451(54.7)$ \\
\hline $\mathrm{RF}+\mathrm{n} / \mathrm{m}(\%)$ & $2983 / 4296(69.4)$ & $6338 / 9492(66.8)$ \\
\hline Erosive disease, $\mathrm{n} / \mathrm{m}(\%)$ & $2480 / 6650(37.3)$ & $\begin{array}{l}4230 / 12,406 \\
\quad(34.1)\end{array}$ \\
\hline Subcutaneous nodules, $\mathrm{n} / \mathrm{m}(\%)$ & $2700 / 7869(34.3)$ & $\begin{array}{l}2886 / 16,640 \\
\quad(17.3)\end{array}$ \\
\hline CDAI, mean (SD) & $13.4(12.8)$ & $11.3(11.9)$ \\
\hline \multicolumn{3}{|l|}{ Current medication use } \\
\hline TNFi biologic & $2924(37.2)$ & $6390(38.4)$ \\
\hline Abatacept & $591(7.5)$ & $980(5.9)$ \\
\hline $\begin{array}{l}\text { Other non-TNFi } \\
\text { biologic/tsDMARD }\end{array}$ & $781(9.9)$ & $962(5.8)$ \\
\hline csDMARD & $7227(91.8)$ & $15,650(93.9)$ \\
\hline \multicolumn{3}{|c|}{ Number of prior biologics/tsDMARDs } \\
\hline 0 & $2583(32.8)$ & $7593(45.6)$ \\
\hline 1 & $2656(33.7)$ & $5592(33.6)$ \\
\hline \multirow{2}{*}{\multicolumn{3}{|c|}{ Number of prior csDMARDs }} \\
\hline & & \\
\hline 0 & 367 (4.7) & $1704(10.2)$ \\
\hline 1 & $2984(37.9)$ & $8016(48.1)$ \\
\hline$\geq 2$ & $4519(57.4)$ & 6938 (41.6) \\
\hline \multicolumn{3}{|l|}{ Patient-reported outcomes } \\
\hline mHAQ score, mean (SD); $n$ & $0.4(0.5) ; 7659$ & $0.3(0.4) ; 16,466$ \\
\hline Pain score, mean (SD); $n$ & $37.2(28.7) ; 7829$ & $31.2(27.5) ; 16,549$ \\
\hline $\begin{array}{l}\text { Global assessment score, mean } \\
\text { (SD); } n\end{array}$ & $35.3(27.3) ; 7830$ & $28.9(26.4) ; 16,549$ \\
\hline Morning stiffness, $\mathrm{n} / \mathrm{m}(\%)$ & $5884 / 7717(76.2)$ & $\begin{array}{l}11,628 / 16,334 \\
(71.2)\end{array}$ \\
\hline
\end{tabular}

Data are $n(\%)$ unless otherwise stated

Anti-CCP, anti-cyclic citrullinated peptide; $C D A I$, Clinical Disease Activity Index; $C O P D$, chronic obstructive pulmonary disease; $c s D M A R D$, conventional synthetic disease-modifying antirheumatic drug; $C V$, cardiovascular; $I L D$, interstitial lung disease; $m H A Q$, modified health assessment questionnaire; $n / m$, number of patients by total number of patients in the analysis; $R A$, rheumatoid arthritis; $R F$, rheumatoid factor; $S D$, standard deviation; $S S$, Sjögren's syndrome; $T N F i$, tumor necrosis factor inhibitor; tsDMARD, targeted synthetic disease-modifying antirheumatic drug

*History of coronary artery disease, myocardial infarction, congestive heart failure requiring hospitalization, acute coronary syndrome, unstable angina, cardiac revascularization procedure, cardiac arrest, ventricular arrhythmia, stroke, transient ischemic attack, or other CV events

${ }^{\dagger}$ History of lung cancer, breast cancer, lymphoma, skin cancer (melanoma and squamous), or other cancer

${ }^{\star}$ Infection required hospitalization or IV treatment activities, pain and discomfort, and anxiety and depression than patients with RA only (Fig. 3).

\section{Discussion}

In the large US-based Corrona RA registry, the prevalence of RA with SS was $30 \%$, which is higher than that previously reported in the US (10.3\%) [8] and toward the higher end of the range reported for Europe (7 to 31\%) [9-11]. The variance in the rates may be due to many reasons, including sample size, the SS classification criteria used, study population differences, and patient—versus physician — reported diagnoses.

Conflicting results have been published regarding whether RA disease duration affects the prevalence of SS, although several studies had low patient numbers $[4,9,11,16-18]$. An analysis of the Oslo Rheumatoid Arthritis Registry (ORAR; $n=631$ ) found no correlation between SS symptoms and RA disease duration [11]; whereas a cross-sectional study in an Indian hospital $(N=199)$ showed that patients with secondary SS had a longer disease duration than those without secondary SS [18]. In addition, a larger study in Spanish patients $(n=788)$ diagnosed by rheumatologists found that the prevalence of SS increased with RA disease duration from an incidence $(95 \% \mathrm{CI})$ of $2.3(1.4,3.7)$ at 2 years to $9.1(6.9,11.8)$ at 10 years [9]. This finding is supported by our study, which to the best of our knowledge is the largest to date investigating patients with RA with SS ( $n=7870)$, and showed that a higher prevalence of RA with SS was observed as RA duration increased.

The comparison of the baseline characteristics showed that compared with patients with RA only, patients with RA with SS were older, more likely female, and had longer RA disease duration. In addition, RA with SS was associated with seropositivity; more severe RA; more health-related difficulties such as pain and anxiety; a lower level of employment; and a greater incidence of other extra-articular manifestations and comorbidities. There are limited data available in the literature regarding the characteristics of patients with RA and SS [8]; however, the data reported here are supported by a smaller cross-sectional study of 85 patients with RA which showed that patients with RA with SS were more likely to be female and have longer disease duration and higher frequency of RF and/or anti-citrullinated protein antibody (ACPA) positivity [8]. Similarly, a single-center study $(n=74)$ found that higher disease scores and frequencies of RF positivity were reported in patients with RA with SS compared with those with either RA or SS alone [4].

In contrast, a small cross-sectional study found no differences between patients with RA with SS $(n=11)$ and those with RA alone $(n=296)$ regarding age, sex, RA disease duration, disease activity score, and ACPA seropositivity; 

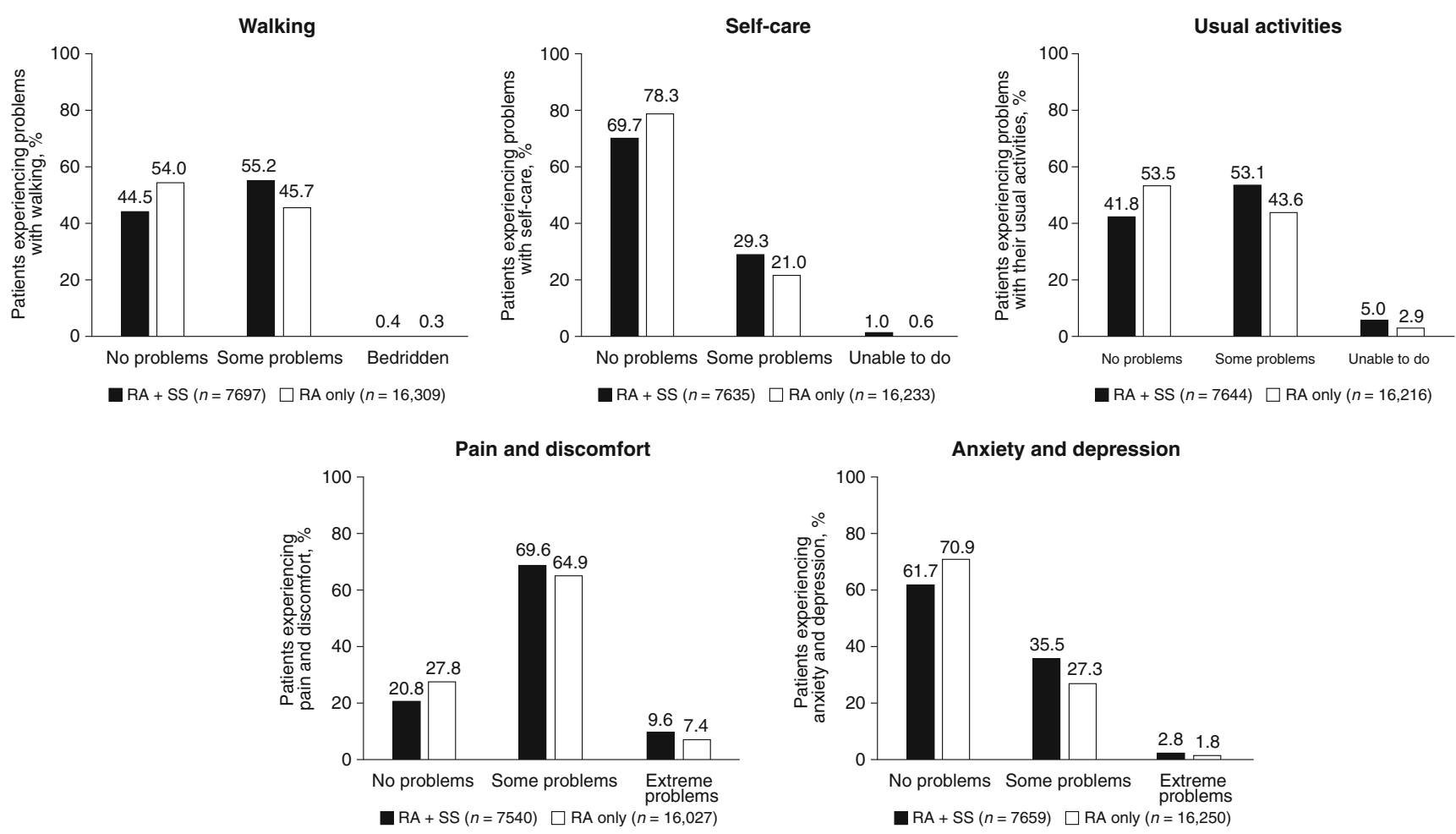

Fig. 3 Health status as measured by the five domains of the EuroQoL 5-dimension questionnaire: mobility, self-care, usual activities, pain/discomfort, and anxiety/depression. Health status was measured at the index date. RA = rheumatoid arthritis; SS = Sjögren's syndrome

however, it showed that patients with RA and secondary SS had a tendency for higher numbers of tender and swollen joints and pain [17]. Data from a Finnish Registry showed that patients with secondary SS $(n=709)$ were more likely to have hematologic malignancies than those with RA alone $(n=$ 9469; standard incidence ratio, $3.1 \%$ vs $1.7 \%$ ) [19]. The differences between groups in these descriptive studies may be a result of the low number of patients with RA with SS in the former study. The low patient numbers make comparisons between studies difficult as differences may be due to SS, factors associated with SS, or the randomness of the data.

A strength of our study is the source of our patient data. Corrona is the largest US disease-registry that collects data directly from both providers and patients at the time of a routine clinical encounter, which allowed for a very large number of patients with RA and SS to be investigated. One potential limitation in every registry-based analysis is whether findings are representative of, and generalizable to, the broader population. Corrona does include rheumatology practices participating throughout the country in rural and urban areas in academic and private settings and with access to broad geographic locations and patients with diverse sociodemographic origins. In addition, prior work compared Medicare patients enrolled in Corrona with those who are not part of the registry and found similar demographic and comorbidity characteristics, supporting the generalizability of the Corrona registry [20]. As our study used a physician-reported diagnosis of SS associated with RA, it is possible that providers may differ in the criteria used to diagnose patients. Differences in diagnosis criteria are shown throughout the literature, suggesting a need for standardized diagnosis criteria for patients with SS and RA which are easy to implement in everyday practice. In addition, patients in the RA alone group required a questionnaire entry for SS (yes/no), potentially leading to under ascertainment.

\section{Conclusions}

In this large, US patient population, patients with RA with SS had a higher disease burden than those with RA alone; a higher prevalence of SS was observed as RA disease duration increased. Identifying specific characteristics of patients with RA with SS may help clinicians to better understand this patient population and the extra-articular manifestations of RA. Additional studies are warranted to further understand the full burden of SS in patients with RA and its impact on clinical and patient-reported outcomes.

Acknowledgments The authors would like to thank all of the patients and providers who have participated in the Corrona RA registry. This study 
was sponsored by Corrona, LLC and funded by Bristol-Myers Squibb. Corrona has been supported through contracted subscriptions in the last 2 years by AbbVie, Amgen, Boehringer Ingelheim, Bristol-Myers Squibb, Celgene, Crescendo, Eli Lilly and Company, Genentech, Gilead, GlaxoSmithKline, Janssen, Merck, Momenta Pharmaceuticals, Novartis, Ortho Dermatologics, Pfizer Inc., Regeneron, Roche, Sun, and UCB. The design and study conduct were a collaborative effort between Corrona and Bristol-Myers Squibb.

Professional medical writing support and editorial assistance was provided by Claire Line, PhD at Caudex, Oxford, UK and was funded by Bristol-Myers Squibb.

Funding information This study was financially supported by BristolMyers Squibb.

Data availability The datasets generated during and/or analyzed during the current study are available from the corresponding author on reasonable request.

\section{Compliance with ethical standards}

This study was carried out in accordance with the Declaration of Helsinki. All participating investigators obtained full board approval for conducting non-interventional research involving human subjects with a limited dataset. Sponsor approval and continuing review were obtained through a central Institutional Review Board (IRB; New England Independent Review Board, NEIRB No. 120160610). For academic investigative sites that did not receive a waiver to use the central IRB, full board approval was obtained from the respective governing IRBs and documentation of approval was submitted to Corrona, LLC, prior to initiating study procedures. All patients provided written informed consent and authorization prior to participating.

Conflict of interest Leslie R. Harrold is an employee of Corrona, LLC, and a shareholder in Corrona, LLC, and has received grant/research support from Pfizer and consulting fees from AbbVie, Bristol-Myers Squibb, and Roche. Ying Shan and Sabrina Rebello are employees of Corrona, LLC. Neil Kramer has nothing to declare. Evo Alemao, Sean E. Connolly, and Sheila Kelly have stock options/bond holdings in, and are employees of, Bristol-Myers Squibb. Joel Kremer has stock options/ bond holdings in, and is an employee of, Corrona, LLC; has received consultancy fees from AbbVie, Amgen, Bristol-Myers Squibb, Genentech, Lilly, Regeneron, Sanofi, and Pfizer; and has received grant/research support from AbbVie, Bristol-Myers Squibb, Genentech, Lilly, Novartis, and Pfizer. Elliot D. Rosenstein has received consultancy fees from Amgen and Bristol-Myers Squibb; has received grant/research support from Myriad Genetics and Novartis; and is on speakers' bureaus for AbbVie, Amgen, and Bristol-Myers Squibb.

Open Access This article is licensed under a Creative Commons Attribution 4.0 International License, which permits use, sharing, adaptation, distribution and reproduction in any medium or format, as long as you give appropriate credit to the original author(s) and the source, provide a link to the Creative Commons licence, and indicate if changes were made. The images or other third party material in this article are included in the article's Creative Commons licence, unless indicated otherwise in a credit line to the material. If material is not included in the article's Creative Commons licence and your intended use is not permitted by statutory regulation or exceeds the permitted use, you will need to obtain permission directly from the copyright holder. To view a copy of this licence, visit http://creativecommons.org/licenses/by/4.0/.

\section{References}

1. Holdgate N, St Clair EW (2016) Recent advances in primary Sjogren's syndrome. F1000Res 5. https://doi.org/10.12688/ f1000research.8352.1

2. Patel R, Shahane A (2014) The epidemiology of Sjogren's syndrome. Clin Epidemiol 6:247-255. https://doi.org/10.2147/CLEP. S47399

3. Mavragani CP, Moutsopoulos HM (2019) Primary versus secondary Sjogren syndrome: is it time to reconsider these terms? J Rheumatol 46:665-666. https://doi.org/10.3899/jrheum.180392

4. He J, Ding Y, Feng M, Guo J, Sun X, Zhao J, Yu D, Li Z (2013) Characteristics of Sjogren's syndrome in rheumatoid arthritis. Rheumatology (Oxford) 52:1084-1089. https://doi.org/10.1093/ rheumatology/kes374

5. Helmick CG, Felson DT, Lawrence RC, Gabriel S, Hirsch R, Kwoh CK, Liang MH, Kremers HM, Mayes MD, Merkel PA, Pillemer SR, Reveille JD, Stone JH, National Arthritis Data W (2008) Estimates of the prevalence of arthritis and other rheumatic conditions in the United States. Part I. Arthritis Rheum 58:15-25. https:// doi.org/10.1002/art.23177

6. Simon TA, Kawabata H, Ray N, Baheti A, Suissa S, Esdaile JM (2017) Prevalence of co-existing autoimmune disease in rheumatoid arthritis: a cross-sectional study. Adv Ther 34:2481-2490. https://doi.org/10.1007/s12325-017-0627-3

7. Alani H, Henty JR, Thompson NL, Jury E, Ciurtin C (2018) Systematic review and meta-analysis of the epidemiology of polyautoimmunity in Sjogren's syndrome (secondary Sjogren's syndrome) focusing on autoimmune rheumatic diseases. Scand J Rheumatol 47:141-154. https://doi.org/10.1080/03009742.2017. 1324909

8. Brown LE, Frits ML, Iannaccone CK, Weinblatt ME, Shadick NA, Liao KP (2015) Clinical characteristics of RA patients with secondary SS and association with joint damage. Rheumatology (Oxford) 54:816-820. https://doi.org/10.1093/rheumatology/keu400

9. Carmona L, Gonzalez-Alvaro I, Balsa A, Angel Belmonte M, Tena X, Sanmarti R (2003) Rheumatoid arthritis in Spain: occurrence of extra-articular manifestations and estimates of disease severity. Ann Rheum Dis 62:897-900. https://doi.org/10.1136/ard.62.9.897

10. Andonopoulos AP, Drosos AA, Skopouli FN, Acritidis NC, Moutsopoulos HM (1987) Secondary Sjogren's syndrome in rheumatoid arthritis. J Rheumatol 14:1098-1103

11. Uhlig T, Kvien TK, Jensen JL, Axell T (1999) Sicca symptoms, saliva and tear production, and disease variables in 636 patients with rheumatoid arthritis. Ann Rheum Dis 58:415-422. https:// doi.org/10.1136/ard.58.7.415

12. Mertzanis P, Abetz L, Rajagopalan K, Espindle D, Chalmers R, Snyder C, Caffery B, Edrington T, Simpson T, Nelson JD, Begley C (2005) The relative burden of dry eye in patients' lives: comparisons to a U.S. normative sample. Invest Ophthalmol Vis Sci 46:4650. https://doi.org/10.1167/iovs.03-0915

13. Alemao E, Saini Y, Bao Y, Rao A, Iannaccone CK, Weinblatt ME, Shadick N (2018) The joint disease burden in patients with secondary Sjögren's syndrome and RA compared to patients with RA only [abstract]. Arthritis Rheum 70(suppl 10):abstract 2506

14. Crilly MA, Johnston MC, Black C (2014) Relationship of EQ-5D quality of life with the presence of co-morbidity and extra-articular features in patients with rheumatoid arthritis. Qual Life Res 23: 1435-1443. https://doi.org/10.1007/s11136-013-0597-0

15. Pincus T, Summey JA, Soraci SA Jr, Wallston KA, Hummon NP (1983) Assessment of patient satisfaction in activities of daily living 
using a modified Stanford Health Assessment Questionnaire. Arthritis Rheum 26:1346-1353

16. Antero DC, Parra AG, Miyazaki FH, Gehlen M, Skare TL (2011) Secondary Sjogren's syndrome and disease activity of rheumatoid arthritis. Rev Assoc Med Bras (1992) 57:319-322

17. Haga HJ, Naderi Y, Moreno AM, Peen E (2012) A study of the prevalence of sicca symptoms and secondary Sjogren's syndrome in patients with rheumatoid arthritis, and its association to disease activity and treatment profile. Int J Rheum Dis 15:284-288. https:// doi.org/10.1111/j.1756-185X.2012.01717.x

18. Santosh K, Dhir V, Singh S, Sood A, Gupta A, Sharma A, Sharma S (2017) Prevalence of secondary Sjogren's syndrome in Indian patients with rheumatoid arthritis: a single-center study. Int J Rheum Dis 20:870-874. https://doi.org/10.1111/1756-185X.13017
19. Kauppi M, Pukkala E, Isomaki H (1997) Elevated incidence of hematologic malignancies in patients with Sjogren's syndrome compared with patients with rheumatoid arthritis (Finland). Cancer Causes Control 8:201-204. https://doi.org/10.1023/A: 1018472213872

20. Curtis JR, Chen L, Bharat A, Delzell E, Greenberg JD, Harrold L, Kremer J, Setoguchi S, Solomon DH, Xie F, Yun H (2014) Linkage of a de-identified United States rheumatoid arthritis registry with administrative data to facilitate comparative effectiveness research. Arthritis Care Res 66:1790-1798. https://doi.org/10.1002/acr. 22377

Publisher's note Springer Nature remains neutral with regard to jurisdictional claims in published maps and institutional affiliations. 